\section{Searching for their} selves

\section{Stuart Sutherland}

The Man Who Mistook his Wife for a Hat. By Oliver Sacks. Duckworth: 1985. Pp.233. £9.95. To be published in the United States in January by Summit, \$15.95.

IN his latest book, the author of Awakenings reports many curious happenings. Perhaps the most surprising is his revelation that one can be a practising neurologist without having read the literature on visual agnosia and without knowing that retrograde amnesia is common in Korsa-

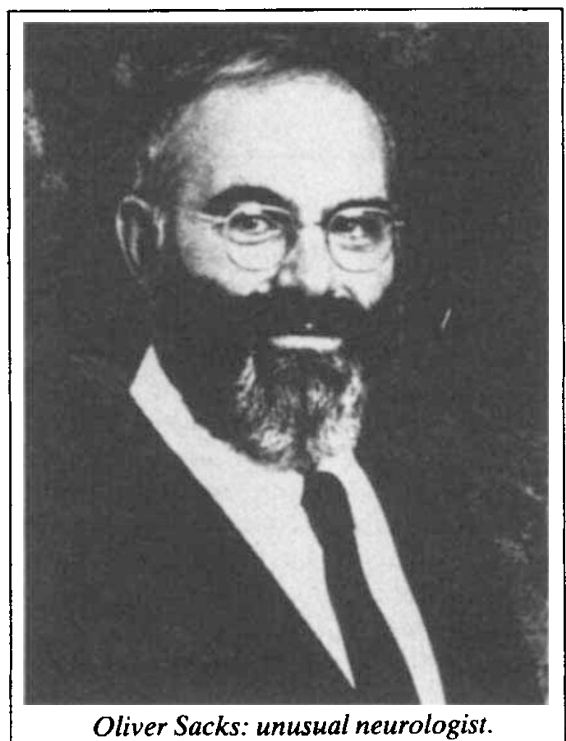

koff's psychosis, and indeed after medial temporal lobe damage in general. Oliver Sacks asserts that he only acquired the knowledge in question after having encountered such cases himself: it is of course possible, judging from The Man Who Mistook His Wife for a Hat, that he had been too busy reading Wittgenstein and Nietzsche to be bothered with the literature of his profession, but one fears he may be having the reader on, a suspicion that the remainder of his book does little to allay.

Dr Sacks recounts with verve and clarity some score of neurological case-histories, all of which make excellent short stories. He describes a wide range of symptoms, ranging from Tourette's syndrome, which is marked by tics, grimaces, curses, and "an odd elfish humour... a and outlandish kinds of play", to those of an idiot savant. His cases have only two unusual features. First, they seem to present symptoms in an exceptionally pure form and do not exhibit the messy confounding of different syndromes so common in such patients. Second, they were treated by a very unusual neurologist, Dr Sacks himself.

$\mathrm{He}$ is unusual in that no matter how devastating the incapacity caused by his patient's brain damage, he always seems able to locate, usually at the first interview, an area in which the patients' "self" is still intact and which they can be encouraged to develop. This may relieve their misery - where they are miserable, since many neurological patients have no understanding of their condition and may even be unnaturally cheerful. Moreover, the development of an intact interest or skill may, according to Sacks, help to alleviate patients' symptoms. He points, for example, to a mentally retarded girl with extremely clumsy body movements, whom he helped find herself through acting: when she was on the stage all her clumsiness disappeared.

Although Sacks's grasp of brain science seems at times a little shaky (for example, Wilder Penfield did not show "beyond doubt" that epileptic transports are direct

\section{Different biology}

\section{Alan Bittles}

Human Sexual Dimorphism. Edited by $\mathbf{J}$. Ghesquiere, R.D. Martin and F. Newcombe. Taylor \& Francis: 1985. Pp.375. $£ 24, \$ 53$.

Although, perhaps inevitably, there is considerable variation in the content and quality of the 18 contributions in a volume of this nature, based on a joint symposium organized by the Society for the Study of Human Biology and the European Anthropological Association, the editors have assembled an informative and very readable collection of papers on this important biological topic. From a purely semantic viewpoint, use of the term sexual dimorphism in the book is often somewhat inappropriate as the parameters can display considerable overlap between the sexes and show greater intra- than intergroup differences. The authors in general have adopted a fairly flexible, if occasionally rather arbitrary, definition for the expression of dimorphism in a species, and for this reason some of the conclusions may not necessarily be definitive.

Allometric analysis is used by a number of contributors in an attempt to unravel the circularity apparent in theories constructed to explain the origins of dimorphism. By scaling brain size to body size in simian primates it is apparent that dimorphism has evolved through reduced body size in females rather than increased male body size. Further, similar studies across a wide range of mammals have shown that brain weight is primarily associated with age at sexual maturity, rather than with lifespan as has been commonly supposed. Possible mechanisms governing embryonic sexual differentiation via $\mathrm{H}-\mathrm{Y}$ antigen secreted by the Sertoli cells, and sex-differentiated behaviour memories of the past rather than fantasies), his message is important and compassionate. He writes, "Our tests are ridiculously inadequate. They only show us defects . . . they do not show us a being conducting itself spontaneously in its own natural way". If we are to believe him, the discovery and promotion of the spontaneous self is particularly important in neurology, but it should surely play a role in all medicine.

The book deserves to be widely read whether for its message, or as an easy introduction to neurological symptoms, or simply as a collection of moving tales. The reader should, however, bring to it a little scepticism, for outside Sacks's clinic, things do not always fall out quite so pat.

Stuart Sutherland is Director of the Centre of Research on Perception and Cognition, University of Sussex, Brighton BNI 9QG,UK. patterns are clearly presented. Given the difficulties inherent in obtaining experimental evidence from human studies, the elegant demonstration in zebra finches of a hormone-influenced dichotomous choice between male and female patterns at single neurone level, and the subsequent translation of the degree of brain masculinization into a behavioural continuum, may be of considerable significance.

While evidence from our hominid ancestors and the australopithecines relating to sexual dimorphism is both limited and literally fragmentary, the existence of dimorphic patterns in Homo sapiens is well established. As expected from the title, human sexual dimorphism is thoroughly assessed in a series of six papers on anthropometric, physiological and behavioural findings from a variety of extant populations in Europe, Africa and Asia. The possibility that apparent dimorphic differences may have arisen as a result of acculturation, rather than being representative of man's basal state, is illustrated in an extensive project conducted on Aboriginal hunter-gathers from Arnhem Land in northern Australia. Somewhat surprisingly, in this population the ageassociated rise in blood pressure is a female, not a male, phenomenon which calls into question many of the assumptions made regarding the basic biology. of our species, derived only from groups living in the developed countries.

Despite the less than perfect reproduction of the camera-ready format, overall this is an impressive publication which should find a ready audience across a wide range of biologists, behavioural scientists and clinicians. It can be recommended both as a source text and an interesting volume in its own right.

Alan Bittles is Senior Lecturer in the Department of Anatomy and Human Biology, Kings College (KQC), University of London, London WC2R $2 L S$, UK. 